\title{
A arte de Romero Britto: uma aproximação estratégica
}

\section{Romero Britto's Art: A strategic approach}

\author{
Giorgio Gilwan da Silva ${ }^{1}$ \\ Laís Lara Vacco $^{2}$ \\ Robson Freire ${ }^{3}$ \\ Marília Matos Gonçalves ${ }^{4}$
}




\section{Resumo}

Este estudo buscou identificar o uso da arte de Romero Britto como estratégia de marketing na comercialização de produtos. Buscou-se conhecer as motivações que levaram as empresas investigadas a utilizarem a arte como estratégia mercadológica. $\mathrm{O}$ tipo de pesquisa caracteriza-se como qualitativa quanto a coleta e descritiva dos dados primários. Foi aplicada uma entrevista com profissionais e proprietários das três empresas selecionadas para esta investigação. Os principais dados da pesquisa revelaram que a arte de Romero Britto é direcionada a um publico especifico, pertencentes às classes econômicas $\mathrm{A}$ e $\mathrm{B}$, e que as ilustrações estampadas nos diversos produtos transmitem percepções sensoriais aos clientes. A despeito das principais conclusões, infere-se que a associação da arte a objetos de consumo, pode ser uma forma de diferenciação utilizada pelas empresas para competir e sobreviver ao longo do tempo. As cores vibrantes e formas alegres das obras aplicadas proporcionou um aspecto positivo e atrativo aos produtos e para as empresas que comercializaram os mesmos, induzindo o consumo.

Palavras-Chave: Romero Britto, arte, arte pop, marketing, estratégia.

\section{Abstract}

This study sought to identify the use of Romero Britto art as a marketing strategy in marketing products. He sought to understand the motivations that led the companies investigated to use art as a marketing strategy. The type of research is characterized as qualitative and descriptive as the collection of primary data. It was applied an interview with professionals and owners of the three companies selected for this investigation. The main survey data revealed that the art of Romero Britto is directed to a specific audience, belonging to socioeconomic classes $A$ and $B$, and that the printed illustrations on various products transmit sensory perceptions to customers. Despite the key findings, it appears that the association of art objects of consumption, can be a form of differentiation used by companies to compete and survive over time. The vibrant colors and cheerful forms of applied works provided a positive and attractive aspect to the products and the companies that marketed the same, inducing consumption.

Keywords: Romero Britto, pop art, marketing, strategy.

ISSN: $1808-3129$

\footnotetext{
${ }^{1}$ Designer Gráfico formado na UDESC, Especialização em Design Gráfico e Estratégia Coorporativa e Mestrado na Engenharia e Gestão do Conhecimento UFSC. Brasil giorgiogilwan@gmail.com

2 UNIVALI, Itajaí, SC, Brasil laislara@gmail.com

${ }^{3}$ UNIVALI, Florianópolis, SC, Brasil robson.freire@univali.br

${ }^{4}$ UFSC, Florianópolis, SC, Brasil marilinhamt@gmail.com
} 


\section{Introdução}

Expressar-se, sentir e pensar. A arte em suas diversas representações compreende aspectos essenciais presentes na natureza humana. Desde o início da civilização até os tempos atuais, as manifestações artísticas influenciaram de modo direto ou indireto o curso da humanidade. Embora se reconheça que este conceito seja amplo e abarque uma variedade de meios e formas de expressão (música, pintura, literatura, dança, fotografia, escultura, dentre outras), este trabalho dedica-se a um movimento em especial, a arte pop. Especificamente investiga o uso deste tipo de arte por algumas empresas como estratégia de marketing, focalizando atenção no caso Romero Britto.

A arte pop surgiu como movimento artístico, em meados da década de 1950, nos Estados Unidos e no Reino Unido. Com a ambição de romper barreiras entre o expressionismo abstrato (movimento anterior), cultivado pela elite e a cultura de massa, um grupo de artistas, representante desse movimento artístico, passaram a produzir obras comerciais e muitas vezes associavam seus trabalhos a produtos de consumo popular, tendo como exemplo o caso Andy Warhol e as sopas Cambpell. Influenciado pela arte pop e pelo cubismo, Romero Britto, nascido em Recife e radicado em Miami, também produz seu trabalho de forma massiva e o associa a diversos produtos. Durante o processo de exposição de seu trabalho na Coconut Grove, Florida, o artista, em 1989, foi convidado a produzir uma pintura para a Absolut Vodka, proposta em que renomados artistas pop como Andy Warhol, Keith Haring, Kenny Scharf e Ed Ruscha trabalharam anteriormente. Esse foi o projeto que o tornou conhecido internacionalmente e reconhecido por suas obras inspiradas na arte pop. Grandes empresas como Grand Manier, Pepsi Cola, Disney, entre outras, passaram a incorporar as pinturas do artista em seus principais projetos. Segundo entrevista publicada pela Revista Época, em 2002, Romero Britto faturou cerca de US\$2 milhões com os contratos de licenciamento.

Com característicos traços geométricos, cores vivas e figuras alegres, o artista tornou seu trabalho uma forma de diferenciação para as empresas que associam sua arte aos produtos. Em face desta problematização apresenta-se a seguinte pergunta de pesquisa: em que medida a arte de Romero Britto vinculada aos produtos pode ser considerada uma ação de marketing? Assim sendo, o objetivo principal desse trabalho é analisar o uso da arte de Romero Britto como estratégia de marketing na comercialização de produtos sob a concessão do artista. Especificamente buscou-se: 1) conhecer as motivações que levaram as empresas investigadas a utilizarem a arte como estratégia mercadológica; 2) distinguir as ações dessas empresas em relação aos produtos com a arte de Romero Britto; e 3) analisar os resultados obtidos com o uso desse tipo de estratégia.

Em nível teórico essa investigação se justifica, pois poderá servir para ampliar a compreensão a respeito da arte, sobretudo, da temática principal desse trabalho que é o movimento da arte pop. Além disso, poderá complementar o acervo de referências da universidade e do próprio curso, servindo como material de futuras consultas acadêmicas. De forma prática, o entendimento sobre a associação de marcas atrela- 
das a elementos artísticos pode ser bastante relevante para as empresas, uma vez que se apresenta como uma forma de fomentar as vendas e atrair consumidores. Esse artigo pode ser caracterizado como qualitativo e utilizou como método de obtenção de dados primários a entrevista em profundidade, realizada com três organizações de abrangência nacional ou regional, que comercializam produtos com a assinatura Romero Britto.

Para facilitar a compreensão, este trabalho foi organizado da seguinte maneira: na introdução apresentou-se uma breve contextualização do assunto, problema de pesquisa, definições dos objetivos e justificativas para sua realização. Em seguida realiza-se a revisão literária que destaca os principais autores e temas, tais como: arte ([1]; [2]); arte pop ([3]; [4]); marketing ([5]; [6]); marketing experiencial ([7]; [8]) e estratégias ([5]; [6]). Após esta fase, são descritos os procedimentos metodológicos, a apresentação das empresas e análise do discurso dos entrevistados. Por fim, são articuladas as considerações finais deste artigo.

artigo.

\section{Fundamentação teórica}

Essa parte do estudo prioriza o levantamento literário. A priori ressalta-se que o recorte deste trabalho focaliza atenção na arte pop com objetivo de estudar o caso Romero Britto.

\section{Arte}

Os sentimentos que levam as pessoas a compreender e aceitar tal reprodução como arte são subjetivos, o que torna difícil sua conceituação. Para Coli ([9], p.8), "arte são certas manifestações da atividade humana diante das quais nosso sentimento é admirativo [...]". Por sua vez, Farthing [2] reforça que ao longo da história, nenhuma sociedade deixou de produzir arte. Desde os primórdios o homem busca expressar-se por intermédio de imagens. As mais antigas obras de arte conhecidas foram feitas há 77 mil anos, através da arte rupestre, afirma o autor. Nessa época, a arte pouco tinha a ver com beleza ou contemplação estética: "a arte era um instrumento mágico e servia ao homem na dominação da natureza e no desenvolvimento das relações sociais" ([1], p.44).

Alguns movimentos como realismo, cubismo, dadaísmo, expressionismo abstrato, arte pop, entre diversos outros, sucederam às pinturas rupestres e segundo Farthing ([2], p.12), "as transformações tecnológicas como o cinema, o carro, a luz elétrica e a aviação influenciaram a arte, as vezes declaradamente". Um movimento que inspirou as obras de Romero Britto e estabelecia temas identificados com consumismo, signos e comunicação de massa [4] foi a arte pop, assim sendo, o item da próxima seção aborda o assunto. Arte Pop

O termo surgiu na década de 1954, pelo crítico Lawrence Alloway e designa "arte popular" ([3] p.160). O movimento surgiu na Inglaterra e nos Estados Unidos, mas em geral são tratados separadamente, porém, ambos estavam vinculadas a momentos de mudanças políticas na Grã-Bretanha e Nos Estados Unidos [4]. Essas mudanças 
oriundas do efeito pós-guerra refletiam uma sociedade propensa ao consumismo guiado pela publicidade. Smith ([3], p. 169) aponta que "tudo na arte pop era - e étransitório e provisório. Ao adotarem essas qualidades, os artistas pop ergueram um espelho onde a própria sociedade se vê refletida".

A proposta da arte pop era ser compreensível a qualquer pessoa que a visse, diferente do expressionismo abstrato, movimento anterior. Aacher [10] reforça que o intuito da maioria dos artistas pop não era demonstrar uma revolta contra a sociedade de consumo, mas contra a distinção artificial dos críticos entre cultura "de elite" e cultura de "massas". E apesar da ambição em romperem essas barreiras, os artistas pop acabaram criando obras com preços elevados conforme a singularidade e autenticidade de cada uma [2].

A repentina ascensão da arte pop foi na década de 1960 e firmou a geração de diversos artistas, entre os principais: Andy Wahrol, Roy Lichtestein e James Rosenquist. ([3], p. 162). A arte pop foi considerada por alguns críticos como um movimento indisciplinado e até mesmo descomprometido, mas McCarthy [4] afirma que foi um dos movimentos centrais, na arte inglesa e norte-americana, que afetou o curso da arte posterior em todo o mundo. Considerando o súbito florescimento da arte pop como um fenômeno que impulsionou o consumo de determinados produtos da época, o tema do próximo item é marketing, pois se trata de uma das áreas de conhecimento que estuda as necessidades do consumidor.

\section{Marketing}

Nessa perspectiva, o chamado marketing de permissão, praticado pelas empresas, consiste na troca de informações entre estas e seus clientes de forma consensual e não intrusiva. Para Garcia e Barbosa ([4], p. 126), uma vez não invadida a privacidade do cliente, este "permitirá, de forma espontânea, que a empresa avance na relação entre ambos Para Kotler [5] e Cobra [6], a origem do marketing se deu com o processo de trocas, nas quais duas ou mais partes oferecem algo de valor para o outro, com o objetivo de satisfazer necessidades e desejos. Ainda Cobra [6] complementa que "a essência do marketing é um estado da mente", uma vez que os profissionais e estudiosos da área observam que o ponto de vista do consumidor é extremamente relevante nesse caso.

Os pensamentos de marketing se modificaram com o passar dos anos. De acordo com Miranda e Arruda [11], na década de 1950 surgiu a escola do Comportamento do Consumidor, identificando três áreas diferentes de pesquisa: psicológico emocional e irracional; determinantes sociais e as decisões da estrutura familiar. Em meados da década de 1960 surgem diversas escolas, dentre elas houve a Escola de Trocas Sociais, focada nas transações de mercado e na troca entre vendedores e consumidores. Por volta dos anos 1980, o Marketing de Relacionado aparece no quadro da criação de lealdade, satisfação e retenção de clientes.

O conceito de Cybermarketing aparece no final da década de 1990 e início de 2000 , visto como ferramenta básica para o relacionamento com os clientes, "representando a evolução mais recente do marketing direto" [11]. O marketing experiencial é uma nova abordagem que surgiu neste século e será explorado na próxima seção. 


\section{Marketing experiencial}

As emoções sempre desempenharam um papel importante no marketing, mas vêm ganhando cada vez mais força [7]. Segundo Cobra e Brezzo [6], o marketing experiencial busca gerar experiências e vivências nos clientes, podendo ser sensoriais ou de sentimento, emocionais ou preceituais, racionais ou de pensamento, de atuação ou relacionais.

Schmitt [8] esclarece que muitas organizações voltaram-se para as técnicas de marketing experiencial e, ainda segundo o autor, há diferentes tipos de experiências como os Módulos Experimentais Estratégicos (MEEs). Cada um deles possui estrutura própria, princípios de marketing e incluem experiências sensoriais (sensação), experiências emocionais (sentimento), experiências cognitivas criativas (pensamento), experiências físicas e de estilo de vida (ação), e experiências de identificação social resultantes da relação com um grupo ou cultura de referência (identificação). Esses estudos privilegiam a compreensão do comportamento irracional e impulsivo de compra ao ser influenciado pelos cinco sentidos: visão, audição, olfato, paladar, tato e até mesmo a integração entre eles.

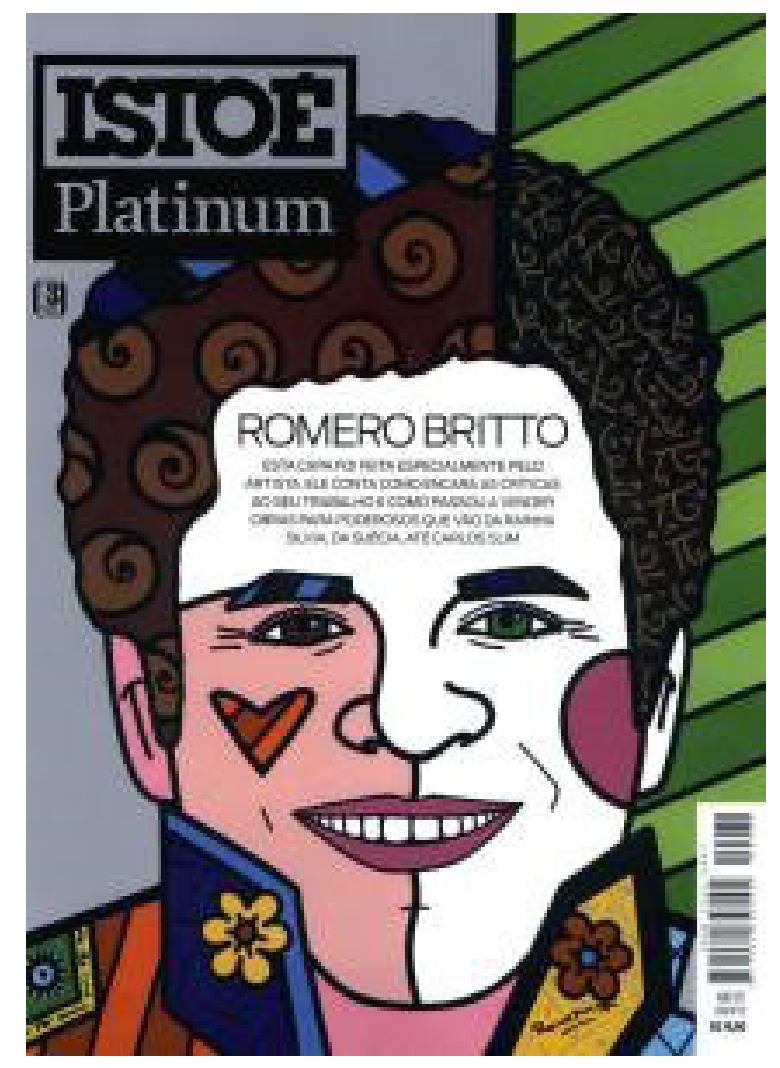


Figura 01: Característica marcante do artista em sua paleta de cores e forma vetorial do uso da imagem.

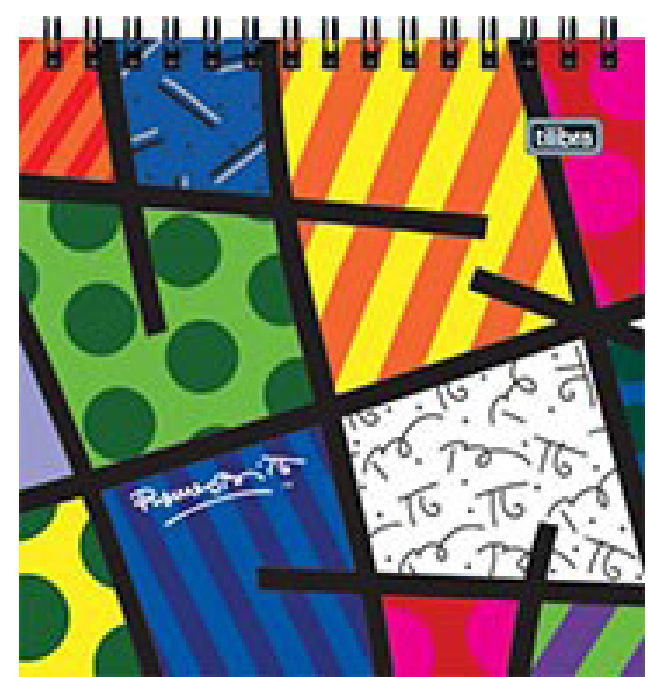

Figura 02: Característica marcante do artista em sua paleta de cores e forma vetorial do uso da imagem em produtos.

Em relação às cores, que se enquadram nas percepções visuais, Farina [12] aponta que as mesmas podem atuar como estimulante ou perturbador na emoção, na consciência e em nossos impulsos e desejos. Ao trabalhar com os sentimentos, [8] os classifica em diversos graus de intensidade, variando de estados de humor medianamente positivos ou negativos até atingir emoções intensas. Para utilizar experiências emocionais com eficiência, é necessário compreender os estados de humor e as emoções da seguinte forma: humores (podem surgir de estímulos específicos, mas no geral o cliente não se torna cientes deles); emoções básicas (alegria, raiva, desgosto e tristeza) e complexas (na maioria originadas em marketing como, por exemplo, a nostalgia que vem sendo bastante explorada pelos profissionais da área). Tendo em vista a técnica do marketing experiencial utilizada pelas organizações como forma estratégica de atrair o consumidor, o próximo tema contextualiza o assunto.

\section{Estratégias}

Embora haja muitos tipos de estratégia de marketing, Michael Porter (apud Kotler, 2000, p. 102) as agrupou em três tipos genéricos; liderança total em recursos (a empresa se esforça para conseguir os menores custos de produção e de distribuição) diferenciação (desempenho em uma área importante de benefícios ao cliente) ou foco (empresa busca liderança em custos ou diferenciação dentro do segmento).

As empresas estão descobrindo parceiros estratégicos para serem efetivas. Para Kotler ([5], p. 103) é difícil alcançar a liderança, nacional ou global, sem alianças estratégicas "apenas o ato de fazer negócios em outro país pode exigir que a organização licencie seu produto [...]". As principais categorias de alianças estratégicas citadas por Kotler [5] são: 1) alianças de produtos ou serviços (licença de uma empresa para outra fabricar seu produto, ou ambas comercializam conjuntamente os produtos); 2) alianças promocionais (empresa concorda em promover um produto ou serviço de outra); 3) alianças de logística (organização pode oferecer serviços de logística para o produto de outra empresa); 4) colaborações em preços: uma ou mais empresas 
podem formar uma colaboração especial para determinação de preços.

Com o propósito de mapear e moldar os negócios e os produtos da empresa, Cobra ([6], p. 40) classifica o planejamento estratégico corporativo com quatro ações iniciais básicas: 1) definição da missão corporativa (determinação do foco de negócio); 2) estabelecimento de unidades estratégicas de negócios suas necessidades e desejos à tecnologia necessária; 3) planejamento de novos negócios visando, entre outros, o crescimento intensivo por meio de estratégias e crescimento integrado de todas as áreas funcionais e crescimento diversificado; 4) planejamento estratégico do negócio (estabelecer a missão e a análise do ambiente externo, levando em conta as forças macroambientais e atores do microssistema). Kotler [5] reforça que as empresas bem sucedidas sabem como se adaptar ao mercado em constante mudança, pois praticam o planejamento estratégico e possuem um compromisso com a conquista e retenção de clientes satisfeitos. Ao considerar a contribuição proporcionada por esta revisão literária, a próxima seção explica as etapas adotadas para a construção deste trabalho.

\section{Procedimentos metodológicos}

Este estudo caracteriza-se como pesquisa exploratória, que visa proporcionar maior domínio sobre o tema a ser abordado [13]. Esta etapa abrangeu o levantamento bibliográfico ([14]; [15]) efetuado por meio de anais de encontros científicos (Intercom - Sociedade Brasileira de Estudos Interdisciplinares da Comunicação e Domínio Público), livros e informações em bases de dados eletrônicos (Google acadêmico e ebooks).

Esta investigação caracteriza-se como qualitativa [16] e utilizou como método de obtenção de dados a entrevista em profundidade, abordagem que ajuda o investigador a recolher respostas a partir da experiência do entrevistado [17]. Na seleção das empresas entrevistadas, foram levados em conta critérios como: participação de mercado; estabelecimento de contrato com o artista; empresa de abrangência nacional ou regional que comercializa diversos produtos da marca Romero Britto. Ainda considerou-se a disponibilidade e acessibilidade das organizações em fornecer as informações que serviram de subsídios para compreensão do assunto. Tendo em vista a confidencialidade e preservação da imagem corporativa, as empresas serão tratadas como empresa 01, 02 e 03.

O processo de investigação, desde o levantamento de dados secundários até a coleta de dados primários e sua análise, abrangeu quatro meses, o que implica em um recorte transversal múltiplo, como explica MALHOTRA [13]. Ressalta-se que o levantamento de dados primários ocorreu entre os dias 19 de agosto a 24 de setembro envolvendo três empresas, sendo a primeira, uma indústria renomada no setor de perfumes e cosméticos no Brasil e outras duas pertencentes ao varejo. A coleta de dados com a Empresa 01 foi realizada via telefone, em função de sua localização ser em outro estado. Nas Empresas 02 e 03, a entrevista ocorreu pessoalmente. A forma de tratamento dos dados primários foi a análise de discurso inglesa, ou seja, prioriza aquilo que se objetiva alcançar quando se conversa com alguém [18]. Também, nesse 
estágio, foi utilizado um sistema de categorização que subsidiou a análise comparativa e possibilitou encontrar similaridades e divergências no discurso dos entrevistados. Assim, as categorias descritas e agrupadas com base no referencial teórico são apresentadas na sequência.

Quadro 01: Categorização para análise extraídas da fundamentação teórica.

\begin{tabular}{|c|c|c|}
\hline Tema Central & Categorias de Palavras e Expressões & Autor (Ano) \\
\hline Arte & $\begin{array}{l}\text { Sentimento; expressar; desenvolvimen- } \\
\text { to das relações sociais; }\end{array}$ & $\begin{array}{l}\text { Coli (1987; Fischer (1987); ); } \\
\text { Farthing (2011) }\end{array}$ \\
\hline Arte Pop & $\begin{array}{l}\text { Consumismo; publicidade; transitório; } \\
\text { compreensível; cultura de massa; pre- } \\
\text { ços elevados; }\end{array}$ & $\begin{array}{l}\text { Smith (1966); McCarthy (2002); } \\
\text { Aarcher (2008) }\end{array}$ \\
\hline Marketing & $\begin{array}{l}\text { Satisfazer necessidades; desejos; consu- } \\
\text { midor; produtos; serviço; valor; }\end{array}$ & Kotler (2000); Cobra (2009) \\
\hline Marketing Experêncial & $\begin{array}{l}\text { Emoções; sensações; experiência; esta- } \\
\text { dos de humor }\end{array}$ & Kotler (2003); Schmitt (2010); \\
\hline Estratégias & $\begin{array}{l}\text { Alianças estratégicas; liderança; diferen- } \\
\text { ciação; foco; planejamento. }\end{array}$ & Kotler (2000); Cobra (2009) \\
\hline
\end{tabular}

Após a escolha dos métodos para análise das entrevistas, os achados advindos dos dados primários foram confrontados com os secundários. Essas análises e discussões são apresentadas no tópico a seguir.

\section{Apresentação das empresas e análises das entrevistas}

Essa seção foi organizada em duas partes para facilitar compressão do assunto. A primeira parte inclui apresentação do artista Romero Britto e informações sobre as empresas pesquisadas. A segunda parte consiste na discussão e análise das entrevistas.

\section{Apresentação do artista e das empresaS}

Nascido em seis de outubro de 1963, na cidade de Recife, Pernambuco, Romero Britto começou a pintar desde cedo. Seus traços são característicos da arte pop e do cubismo e de acordo com site oficial do artista, as cores e formas utilizadas em suas obras, são chamadas, por colecionadores e admiradores, de "arte da cura". Seu trabalho está presente em cem galerias no mundo e devido a sua popularização no âmbito das artes plásticas, em 2005, foi nomeado embaixador das artes do Estado da Flórida pelo ex-governador Jeb Bush. Mais de mil trabalhos foram feitos para diversas empresas, tais como a Microsoft, Audi, Xbox, Unilever (Omo), entre outras. Em entrevista à revista Pequenas Empresas \& Grandes Negócios, Romero Britto afirma ter uma equipe com mais de oitenta pessoas trabalhando em diversas áreas de sua empresa. Os critérios de aceitação para um projeto de licenciamento são analisados de acordo com perfil da organização "tem coisas de que eu realmente gosto, empresas que têm a ver com a minha arte, então eu faço", afirma o artista [19].

Como citado na seção metodológica, as empresas selecionadas atenderam os 
pré-requisitos relativos ao contrato de licenciamento direto com o Romero Britto, comercializam seus produtos regionalmente e possuem um mix variado de produtos com a marca do artista. Além disso, foi levado em consideração a disponibilidade e acessibilidade dessas empresas em fornecer as informações pertinentes a essa investigação.

A fim de facilitar o entendimento sobre as empresas investigadas, o quadro 02 demonstra de forma sintética as características mais relevantes das unidades de análise. Como citado anteriormente, as empresas serão tratadas como empresa 01, 02 e 03, visando manter o sigilo e preservar suas respectivas imagens.

Quadro 02: Principais características das empresas entrevistadas

\begin{tabular}{|l|l|l|}
\hline Empresas & Segmento & Tempo de atuação no mercado \\
\hline Empresa 01 & Perfumes e Cosméticos & 35 anos \\
\hline Empresa 02 & Loja de Presentes & 10 anos \\
\hline Empresa 03 & Acessórios e Bolsas & 9 anos \\
\hline
\end{tabular}

\begin{tabular}{|l|l|l|l|}
\hline Empresas & Número de filiais & Público Álvo & Abrangência \\
\hline Empresa 01 & 867 & B e C & Nacional \\
\hline Empresa 02 & Nenhuma & A e B & Regional \\
\hline Empresa 03 & 25 & A e B & Nacional \\
\hline
\end{tabular}

A Empresa 01, que atua na área de perfumes e cosméticos, realizou uma campanha no período de julho de 2010 até junho 2011 em que a arte de Romero Britto estampou produtos, tais como: perfumes, velas aromatizadas, bolsas, splashs de banho e nécessaire. No caso da compra de qualquer outro produto da loja, o cliente ganhava uma sacola produzida com as ilustrações do artista. Além disso, como parte da campanha, todas as filiais foram decoradas e adesivadas com as ilustrações de Romero Britto.

Em relação à Empresa 02, loja de presentes e boutique masculina, um mix de produtos licenciados pelo artista é comercializado seguindo tabela de preços da importadora. Entre eles aponta-se: canecas, bules, porta-retratos, bandejas, taças, pôsteres, réplicas, porta-bolsas, botas de enfeite, porta-cartões, espelhos portáteis, copos de dose de bebida alcoólica, cinzeiros, entre outros enfeites.

A Empresa 03, que atua no segmento de acessórios e bolsas, comercializa malas de viagem com a arte de Romero Britto há aproximadamente um ano e meio, sendo que sua filial está na cidade de Balneário Camboriú há dois anos. A figura a seguir ilustra os produtos referentes às empresas pesquisadas. 


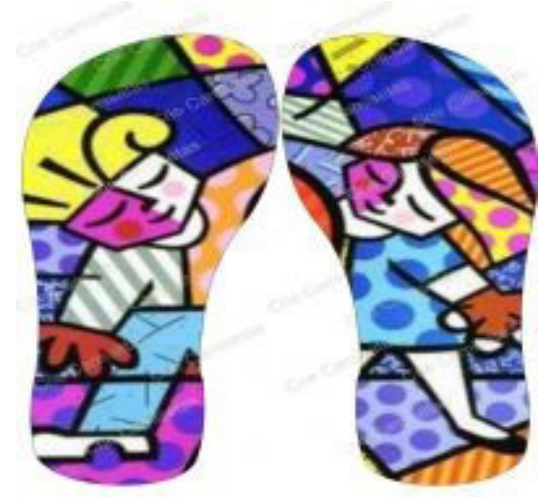

Figura 03: Produto comercializado nas três empresas pesquisadas

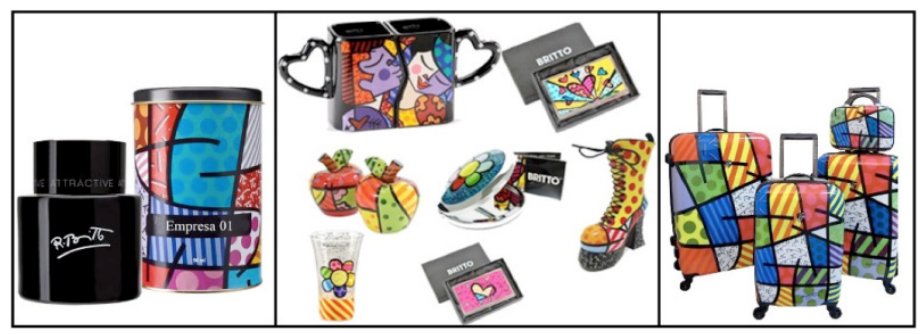

Figura 04: Produtos comercializados nas três empresas pesquisadas.

A imagem foi dividida em três quadros, o primeiro apresenta a embalagem do perfume comercializado na Empresa 01; seu rótulo foi alterado visando sigilo da marca. O quadro central demonstra alguns itens pertencentes ao mix de produtos da Empresa 02 e o terceiro quadro apresenta o jogo de malas revendido na Empresa 03.

\section{Análises das entrevistas}

Com o propósito de obter uma melhor compreensão e facilitar a análise de discurso dos participantes da entrevista em profundidade, os dados primários coletados foram organizados segundo os objetivos específicos, pré-definidos no início desta investigação. Sustentou esta fase do trabalho um sistema de categorização, visando manter coerência, unicidade e imparcialidade na forma de tratar os achados da pesquisa. A análise da entrevista em profundidade foi realizada com base no quadro 01 de categorias apresentado anteriormente na seção relativa aos procedimentos metodológicos.

Inicialmente buscou-se conhecer as motivações que levaram as empresas investigadas a utilizarem a arte como estratégia mercadológica. O departamento de marketing da Empresa 01 afirmou que a arte de Romero Britto foi empregada nas embalagens de seus produtos, visando o reposicionamento da marca e também atingir as classes econômicas A e B, visto que seu público alvo é B e C. A entrevistada ainda acrescenta que escolheram o artista, pois ele estava em ascensão na mídia. Ao utilizar sua arte, o público $B$ e $C$ também se sentiu favorecido e muitos clientes que não o conheciam passaram a receber informações sobre a história e as obras do artista. Segundo ela "para o público que não o conhecia nós desenvolvemos um briefing pra que as vendedoras estudassem [...] toda aquela história, conceito e ensinassem para os clientes [...] Para o cliente que já conhecia, nossa, às vezes eles queriam comprar 
as sacolas, comprar a caixa...".

Outra informação é que a empresa buscou a arte de Romero Britto para transmitir uma imagem mais jovem, alegre e divertida da marca, motivando o consumidor para a compra. Esses são alguns dos preceitos do marketing experiencial, que de acordo com Schmitt [8], Cobra e Brezzo [20] pode gerar experiências sensoriais, emocionais, cognitivas criativas, físicas e de identificação social.

O proprietário da Empresa 02 afirmou que a loja de presentes está em constante busca por novidades e diferenciação. Assim sendo, os produtos licenciados de Romero Britto se apresentam como uma forma de acrescentar isso à loja e divulgar, também, o trabalho do artista "você tem que levar alegria e ele usa esses símbolos da alegria, do amor, da natureza. E como ele consegue trazer isso para os objetos, através dos objetos a gente consegue levar isso para as pessoas", complementou. Isso reforça a abordagem de Farina [12], ao explicar que as sensações produzidas por determinadas cores podem estimular as emoções, foco do marketing experiencial. A gerente da Empresa 03 não soube informar o motivo de a loja possuir as malas com as ilustrações do artista. Ela afirmou que a decisão e seleção dos produtos para venda é feita pela matriz da loja, localizada em São Paulo.

Ainda de acordo com o primeiro objetivo específico, foi possível identificar similaridades entre as empresas em se tratando de aceitação e reconhecimento do público. Na Empresa 01 houve resultados positivos no período da campanha e de acordo com a entrevistada, o público conhecia o artista e consumia as embalagens que continham suas ilustrações. A funcionária da Empresa 02 explicou que são poucas as pessoas que não reconhecem os traços de Romero Britto e acrescentou "os clientes já chegam, querem o Romero Britto; que acham lindo, maravilhoso; ficam felizes que a gente tá trabalhando com o produto". No entanto, identificou-se na empresa 03, que alguns clientes deixam de adquirir os produtos devido à falta de conhecimento sobre o artista e ao alto custo dos mesmos. O segundo objetivo específico buscou distinguir as ações dessas empresas em relação aos produtos com a arte de Romero Britto. Para a entrevistada da Empresa 01 não houve campanha específica divulgando os produtos com as ilustrações do artista. Embora a respondente tenha afirmado isso, ao averiguar as ações realizadas pela empresa, encontrou-se um comercial veiculado na televisão em que a atriz Débora Secco anuncia a campanha de natal e apresenta a embalagem com a arte de Romero Britto, como ilustra a imagem abaixo:

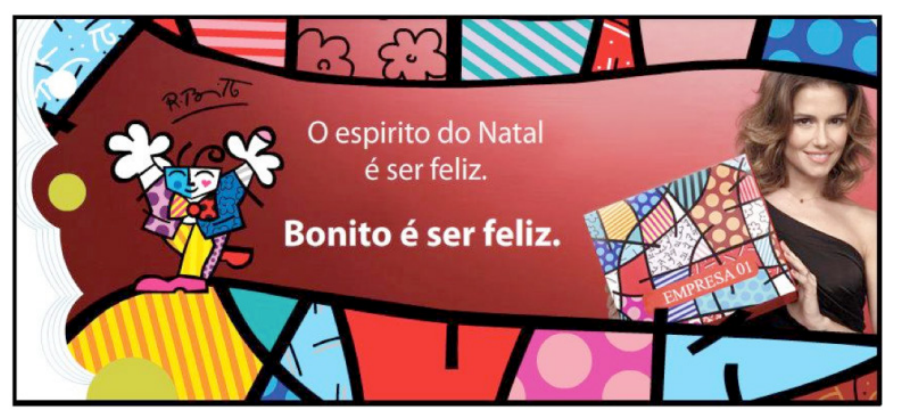

Figura 05: Peça de divulgação veiculada nas mídias online

Outra ação encontrada foi a adesivagem de todas as filiais com desenhos do artista, o que gerou maior fluxo de pessoas no ponto de venda e, segundo a respon- 
dente "os concorrentes mesmo iam lá para ver o que que era aquilo [...]".

No que se refere à Empresa 02 , a atendente afirma colocar os produtos na vitrine, pois suas cores chamativas atraem as pessoas que circulam pelo local. A Empresa 03 não informou as estratégias utilizadas, no entanto, durante o período de coleta de dados, as malas estavam expostas próximas à vitrine. Como confirma Porter (apud Kotler, 2000) o foco, no sentido de a empresa buscar diferenciação dentro do segmento-alvo e a concentração em desempenhar benefícios ao cliente, se caracterizam como pensamentos estratégicos.

O terceiro objetivo específico priorizou analisar os resultados obtidos a partir do uso da arte como estratégia mercadológica. Com isso, observou-se que nas três empresas houve afirmações sobre maior rotatividade na loja e procura pelos produtos que continham as ilustrações do artista. A Empresa 01 citou como positiva a ação da campanha e utilizaram a adesivagem nas lojas para atrair os clientes, gerando assim, maior fluxo de pessoas no local. No caso da Empresa 02, conforme citado anteriormente, a vitrine é utilizada como forma de sedução de clientes, atraindo maior o fluxo de interessados pelos itens da loja. Segundo a entrevistada "as peças chamam bastante atenção pelo colorido, da alegria, que o Romero Britto têm nessas peças dele". Por sua vez, a Empresa 03 relatou que embora os produtos despertem interesse e desejo de compra nos clientes, aqueles que não conhecem o trabalho do artista, optam pela concorrência.

Ainda em relação ao alcance do terceiro objetivo, os contratos de venda para os produtos do artista variavam segundo as formas de comercialização das empresas. No caso da Empresa 01, realizou-se contrato direto de licenciamento com o artista. A profissional do setor de marketing informou que é possível que tenha sido por meio do pagamento de royalties5, mas não soube informar com exatidão o valor ou percentual de vendas. Contudo, acrescenta-se que os produtos da campanha tiveram acréscimo no valor total em relação aos já comercializados na loja, devido à arte ter sido produzida especificamente para cada item. Por se tratar de lojas pertencentes ao varejo, as Empresas 02 e 03 compram os produtos de importadoras que fornecem certos valores de referência.

Em relação aos percentuais de faturamento, somente a empresa 02 soube informar; representa cerca de dez por cento das vendas da loja e o proprietário explica que esse percentual "é muito para uma loja que tem três mil itens". Vale ressaltar que além dos produtos utilizados como enfeites, os itens utilitários, como canecas, chaleiras, porta-bolsas, porta-cartões entre outros, são os mais comercializados.

Ao questionar a Empresa 01 sobre outra possível campanha com as obras do artista, a profissional do setor de marketing informou que não há pretensões para o momento, pois as ações desenvolvidas pela empresa envolvem um ciclo variado de artistas, mas essa possibilidade não foi descartada. Ainda para as Empresas 02 e 03, as encomendas são feitas de acordo com a rotatividade dos produtos e ambas possuem pretensão de mantê-los em suas lojas. $O$ proprietário da empresa 02 acrescentou que irá adquirir mais produtos com estampa de outros artistas.

\section{Considerações finais}


Este trabalho teve como premissa analisar a utilização da arte de Romero Britto como estratégia de marketing em determinadas empresas. Na busca de aprofundamento e aprendizado teórico, levantou-se dados literários sobre as variáveis deste estudo: arte, arte pop, marketing, marketing experiencial e estratégia.

Quanto aos objetivos específicos que direcionaram essa pesquisa, o primeiro, visou conhecer as motivações que levaram as empresas investigadas a utilizarem a arte como estratégia mercadológica. Aponta-se o uso de ações de marketing experiencial à partir das ilustrações do artista. As cores vibrantes e formas alegres da obra de Romero Britto transmitem uma imagem positiva aos produtos e para as empresas que comercializaram os mesmos. Outro ponto relevante foi que a Empresa 01, com a associação de marcas, conseguiu conquistar uma nova fatia de mercado pertencente às classes A e B. A atratividade existente entre o consumidor e os desenhos do artista também fazem parte do conjunto de ações para atingir o mercado-alvo destas empresas.

Distinguir as ações utilizadas pelas empresas vinculadas aos produtos contendo a arte de Romero Britto, foi o pressuposto do segundo objetivo. Identificou-se nas empresas investigas: adesivagem da loja; capacitação dos funcionários para atender os clientes que não conheciam o artista; entrega de brindes com ilustrações de Romero Britto; propaganda com o uso de celebridade; exposição privilegiada dos produtos na vitrine e ampliação do mix de produtos com esse apelo.

Relativo ao terceiro objetivo específico, que buscou analisar os resultados obtidos a partir do uso da arte pelas empresas estudadas, os entrevistados declararam que houve maior visibilidade, aumento de interesse e fluxo de pessoas nos pontos de venda. Outro fator é a funcionalidade dos mesmos, uma vez que os itens utilitários são mais requisitados. Esses produtos muitas vezes possuem alto valor agregado, por consequência, aumentam o faturamento, bem como, possibilitam a diferenciação e conquista de uma nova fatia de mercado. Em síntese, os resultados indicam que a temática estudada se trata de uma ação de marketing vinculada ao estabelecimento de alianças e aproximação estratégica entre empresas e artista, haja vista que a associação da arte a objetos de consumo é uma forma diferenciada de as empresas adquirirem personalidade e agregar valores aos produtos, além do retorno financeiro. Outra constatação, é que o preço desmotiva alguns clientes que desconhecem o trabalho do artista. Ressalta-se ainda que embora as empresas possuam formas de vendas distintas entre si, os achados levam a concluir que a associação da arte de Romero Britto aos produtos é positiva quando direcionada a determinado público-alvo. Nesse sentido, a Empresa 01 não afirmou repetir a campanha, no entanto, as empresas 02 e 03 pretendem manter as vendas, e ainda segundo o proprietário da empresa 02, adquirir novos produtos contendo ilustrações de outros artistas. As motivações e estratégias associadas à arte não são explícitas em todos os casos, contudo, a fundamentação teórica contribuiu para dirimir dúvidas referentes às ações das empresas.

Como limitações pode-se considerar a falta de algumas informações não fornecidas pelos entrevistados, visto que as mais complexas caberiam a outros setores não acessíveis das empresas, como por exemplo, o faturamento e o percentual de licenciamento de produtos. Mesmo sabendo que em tempos de informação digital o contato se tornou mais viável, outra restrição a ser apontada refere-se ao aspecto 
geográfico, visto que o artista referenciado mora em outro país e não retornou contato através da internet; seu acesso seria de grande relevância neste estudo. Além disso, no levantamento que compreendeu o período entre julho à outubro de 2012 , foram encontrados poucos estudos abordando as variáveis marketing, pop arte e até mesmo, Romero Britto. Um último elemento limitante a ser considerado trata-se do acesso à outras empresas que não se mostraram acessíveis.

Como sugestão para futuras investigações, recomenda-se que a pesquisa seja aplicada com maior número de empresas que utilizam esse tipo de aliança estratégica.

Também indica-se a escolha de outros artistas que associem seus trabalhos às empresas, a fim de analisar o uso de suas ilustrações como estratégia mercadológicas.

\section{Referências}

[1] FISCHER, Ernst. A Necessidade da Arte. Rio de Janeiro: Guanabara, 1987.

[2] FARTHING, Stephen. Tudo sobre arte. Tradutor: Paulo Polzonoff. Rio de Janeiro: Sextante, 2011.

[3] LUCIE-SMITH, Edward. Arte Pop. 1966. In: STANGOS, N. Conceitos da Arte Moderna. Rio de Janeiro: Jorge Zahar, 1994. P. 160-169.

[4] MCCARTHY, David; NUNES, Otacílio. Arte Pop. São Paulo, Sp: Cosac \& Naify Edições, 2002.

[5] KOTLER, Philip. Administração de Marketing: a edição do novo milênio. 10. ed. São Paulo, SP: Pearson Prentice Hall, 2000.

[6] [20] COBRA, Marcos. Administração de marketing no Brasil. 3. ed. Rio de Janeiro, $\mathrm{RJ}$ : Elsevier, 2009.

[7] KOTLER, Philip. Marketing de A a Z: Conceitos que todo professional precisa saber. 7. Reimpressão. Rio d Janeiro: Elsevier, 2003

[8] SCHIMITT, Bernd H. Marketing experiencial. São Paulo: Nobel, 2002.

[9] COLI, Jorge. O que é arte. 8. ed. São Paulo: Brasiliense, 1981

[10] AAKER, David A. Marcas Brad Equity Gerenciando o valor da marca. Tradutor: André Andrade. São Paulo: Elsevier Editora, 1998. 10a reimpressão.

[11] MIRANDA, Danielle Miranda de Oliveira Arruda. Revista Interdisciplinar de Marketing, v.3, n.1, Jan./Jun. 2004. 
[12] FARINA, Modesto. Psicodinâmica das cores em comunicação. 4. ed. São Paulo, SP: E. Blucher, 1990, 2005. 2

[13] MALHOTRA, Naresh K. Pesquisa de marketing: uma orientação aplicada. 4. ed. Porto Alegre, RS: Bookman Companhia, 2006.

[14] MATTAR, Fauze Najib. Pesquisa de marketing: metodologia, planejamento. 5. Ed. São Paulo: Atlas, 1944.

[15] STUMPF, Ida Regina C. Pesquisa bibliográfica. In: DUARTE, Jorge; BARROS, Antonio. Métodos e Técnicas de Pesquisa em Comunicação. São Paulo: Atlas, 2009. Cap. 3.

[16] MCDANIEL, Carl D.; GATES, Roger H. Pesquisa de marketing. São Paulo: Thomson, 2006.

[17] DUARTE, Jorge; BARROS, Antonio. Métodos e técnicas de pesquisa em comunicação. São Paulo: Editora Atlas. 2. ed. 2009. Cap. 4.

[18] MANHÃES, Eduardo. Análise de discurso. In: DUARTE, Jorge; BARROS, Antonio. Métodos e Técnicas de Pesquisa em Comunicação. São Paulo: Atlas, 2009. Cap. 19.

[19] O EFEITO MULTIPLICADOR DE ROMERO BRITTO. Pequenas Empresas \& Grandes Negócios: Editora Globo, outubro, 2012.

[21] ARCHER, Michael. Arte Contemporânea: uma história concisa. São Paulo: Martins Fontes, 2001.

[22] COVALESKI, Rogério. Intersecções artístico-comunicativas: o rompimento de fronteiras entre artes e comunicação. Comunicon, 2011. Disponível em: http://www. covaleski.com.br/blog/artigos/estetica.pdf Acesso: 19 de agosto de 2012.

[23] VEIGA, Aida. Fartura de cor e lucro: com sua arte pop de qualidade, Romero Britto conquista o mundo dos licenciamentos. Época, 2002. Disponível em: http:// revistaepoca.globo.com/Revista/Epoca/0,EDR52004-6014,00.html. Acesso em: 23/08/2012.

[24] VIEIRA, Stalimir. Marca: o que o coração não sente os olhos não vêem: (reflexões sobre marketing e ética). Rio de Janeiro, RJ: Ed. PUC-Rio; São Paulo, SP: Edições Loyola, 2001.

[25] Royalties. Disponível em: <http://www.senado.gov.br/noticias/agencia/infos/Inforoyalties_.htm> Acesso em: 05/10/2012 Critério de Classificação E c o nômica Brasil. Disponível em: http://www.abep.org/novo/Content.aspx?ContentID=301 Acesso em: 05/10/2012 
[26] SMITH, W. R. Product diferentiation and market segmentation as alternative marketing strategies. Jornal of Marketing. Jul. 1956.

[27] PICOLI, Julia Isoppo. Coolhunting: pesquisador e suas metodologias. EnModa Escola de Empreendedores, 2009. Disponível em http://migre.me/eSnrL. Acesso: 06 maio 2013.

[28] GLADWELL, Malcom. O Ponto da Virada. Rio de Janeiro: Sextante, 2009.

[29] MATATHIA, Ira. O'REILLY, Ann. SALZMAN, Marian. Buzz: a era do marketing viral. São Paulo: Cultrix, 2003.

[30] MACHADO, R. AFONSO, H. O coolhunter e os critérios de noticiabilidade na editoria de moda da revista Capricho. In: CONGRESSO DE CIÊNCIAS DA COMUNICAÇÃO NA REGIÃO SUL/JORNALISMO, 13, 2012, Chapecó. Anais eletrônicos... Chapecó: Intercomsul, 2012. Disponível em http://migre.me/eSnpy. Acesso em: 13 março 2013.

[31] JUNCKES, E. R. A Prática do Cool Hunting na Empresa Lancaster. 2010. 59 f. Trabalho de Conclusão de Curso (Relatório de Estágio) - Universidade Regional de Blumenau, Santa Catarina, 2010. Disponível em http://migre.me/eSnm9. Acesso em: 12 março 2013. 